\title{
GLOBAL NAVIGATION SATELLITE SYSTEM (GNSS): A UTILITY FOR SUSTAINABLE DEVELOPMENT IN GHANA
}

\author{
C. Fosu', Y. Poku-Gyamfi ${ }^{2}$ and G. W. Hein ${ }^{3}$ \\ ${ }^{1}$ Department. of Geomatic Engineering, \\ Kwame Nkrumah University of Science and Technology, Kumasi, Ghana \\ ${ }^{2}$ Building and Road Research Institute Kumasi, Ghana \\ ${ }^{3}$ Institute of Geodesy and Navigation, University FAF Munich Germany
}

\begin{abstract}
The rapid spread of modern information and communication technologies (ICT) is dependent on the unprecedented increase in information relating to our natural, economic and social environment, and for Ghana and Africa to be in tune with the current trends in ICT, spatial information and methods to acquire them should be our priority. GNSS is therefore the obvious choice. This technology has an enormous potential to contribute to the management of environment, natural disasters, provide food security, emergency response, improve the efficiency in surveying and mapping. Land, water and air navigation will undergo a dramatic improvement with the application of GNSS. This is just to mention a few of the expected benefits. This paper focuses on the benefits to be derived by Ghana as a developing country and Africa in general from the introduction of a functional Multipurpose Global Navigation Satellite System. It specifically highlights the needed basic infrastructure for setting up a Continuously Operating reference System and the need for acquiring the necessary infrastructure to utilize the European Satellite-Based Augmentation System (SBAS), EGNOS. Areas of probable application and benefits have been outlined and the necessary considerations for a successful implementation and its sustenance have been suggested. It looks at how this space technology can support our sustainable development as developing nations.
\end{abstract}

Keywords: Augmentation, GNSS, Information, Infrastructure, Satellites

\section{INTRODUCTION}

Global Navigation Satellite System (GNSS) is composed of two operational space satellite systems, the American GPS and the Russian GLONASS as well as the in-coming European GALILEO, which is supposed to be operational in 2008. It also includes the various regional aug- mentation systems, Wide Area Augmentation System (WAAS) of the USA, Multi Satellitebased Augmentation System (MSAS) of Japan, European Geo-stationary Navigation Overlay Service (EGNOS) of the European Tripartite Group consisting of European Space Agency (ESA), European Commission (EC) and THE

132 Journal of Science and Technology, Volume 27 no. 2, August, 2007 
European Organization for the Safety of Air Navigation (EUROCONTROL).

This space technology has benefited various countries in their developmental activities by improving the quality of life of their people in a more sustainable manner. This is what Ghana needs, as a nation, for the long sought for sustainable development. The rapid spread of modern information and communication technologies (ICT) is dependent on the unprecedented increase in information relating to our natural, economic and social environment, and for Ghana to be in tune with the current trends in ICT, spatial information and methods to acquire them should be our priority. GNSS is therefore the obvious choice. This technology has an enormous potential to contribute to the management of environment, natural disasters, provide food security, emergency response, improve the efficiency in surveying and mapping. Land, water and air navigation will undergo a dramatic improvement with the application of GNSS. This is just to mention a few of the expected benefits.

\section{AFRICA'S GEOGRAPHICAL POSITION AND SBAS}

With its position as almost at the centre of the earth, that is closest to longitude $0^{\circ}$ and latitude $0^{\circ}$, Ghana is covered by the footprints of two of the prominent Space based Augmentation systems, WAAS and EGNOS.

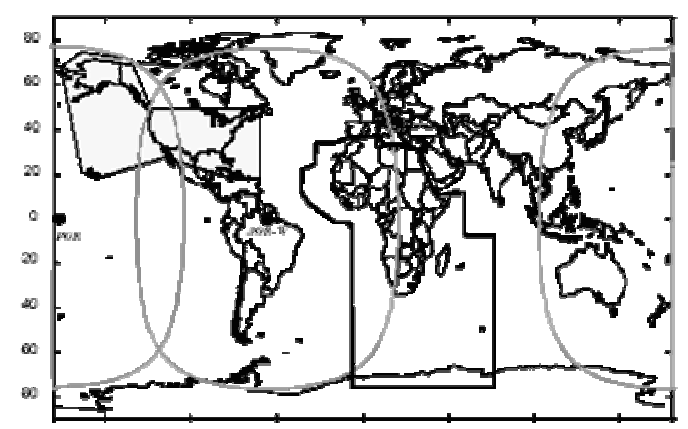

Fig. 1a: Footprints of WAAS
Ghana has got a triple coverage from the three EGNOS geo-satellites, INMARSAT-III AOR-E, ESA's ARTEMIS and INMARSAT III F5 respectively at $21^{\circ} 30^{2} \mathrm{E}, 15^{\circ} 30^{2} \mathrm{~W}$ and $65^{\circ} 30^{2} \mathrm{E}$, all on the equator.

These Satellite-Based Augmentation Systems e.g. WAAS and EGNOS improve the accuracy, availability, integrity and continuity of service of the signals from the satellite. The accuracy of the GPS until US President Bill Clinton put off the Selective Availability (SA) in 2000, was $100 \mathrm{~m}$ at $95 \%$, but by that act it was improved to $20 \mathrm{~m}$ and this is still not good enough for most applications. This can be further improved by introducing an augmentation system; the installation of Ranging and Integrity Monitoring System (RIMS) during the EGNOS test in July 2002 in Dakar, was a remarkable success. (EC, ESA) with even some areas in North-western corner of Ghana achieving Vertical Navigation System Error VNSE (95\%) 10m (see Figure 2.) This compares well with what pertains in Europe (see Figure 3.)

\section{INFRASTRUCTURAL NEEDS THE NATIONAL DATUM}

The linking of the GPS (GNSS) coordinates, which is in the World Geodetic System 1984 (WGS84) to the national datum, is an essential requirement for the establishment of GNSS in a country. There is the need therefore to work on

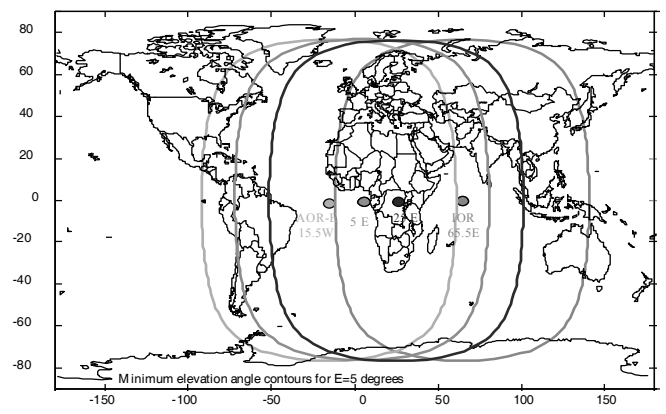

Fig. 1b: Footprints of EGNOS 


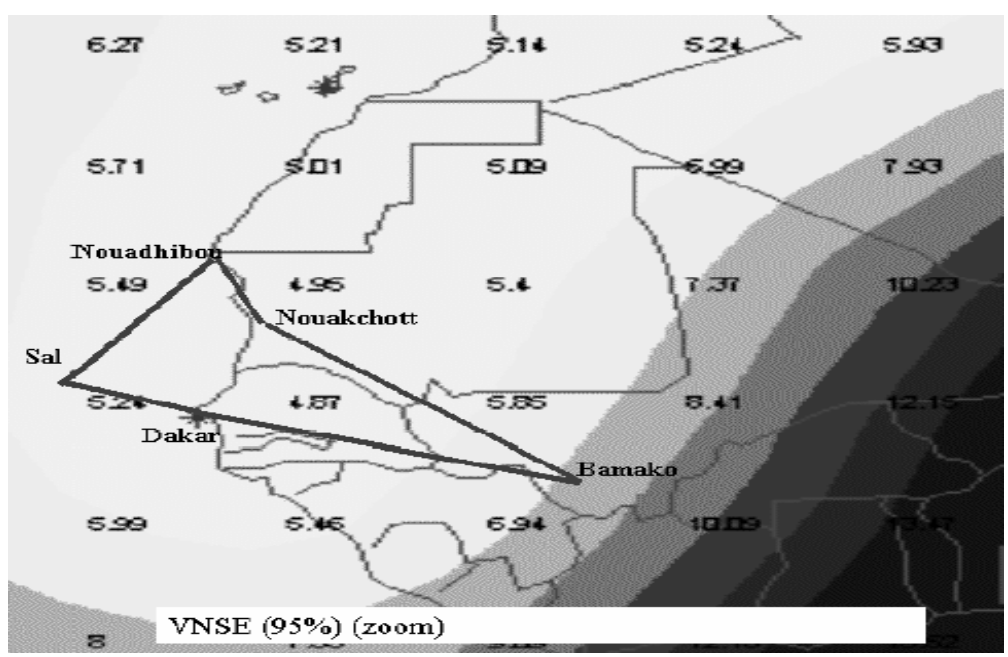

Fig. 2: Showing the performance of EGNOS System Test bed ESTB in Dakar July 2002 (Courtesy: www.navcen.uscg.gov/cgsic/meetings/8EGNOSAfrica\%202002.pdf)

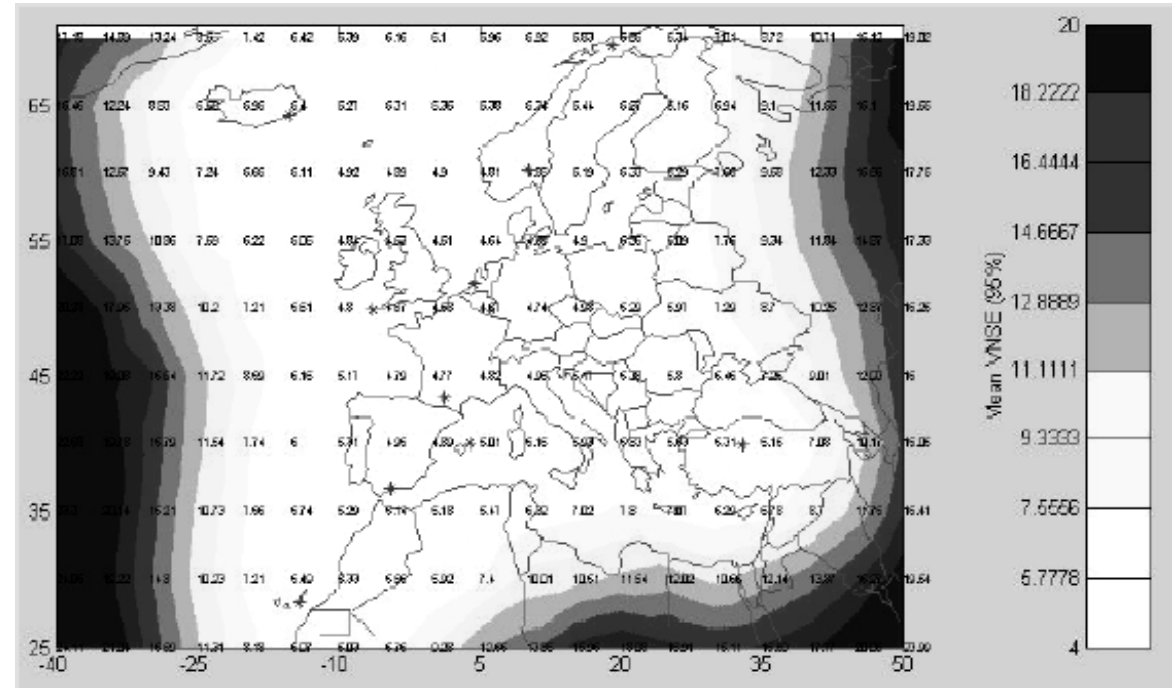

Fig. 3: Performance (VNSE) of ESTB coverage with 10 RIMS cover of the EGNOS in Europe (Courtesy: www:esamultimedia.esa.int/docs/egnos/estb/Publications/2nd\% 20ESTB\%20workshop/ ESTB\%20Status\%20and\%20Evolution.PDF)

acceptable national transformation parameters, to convert the GNSS data onto the national coordinate system and vice versa. These parameters will be used as a standard for all GNSS activities. This effort will compliment that of the proposed African Reference Frame (AFREF) and the West

134 Journal of Science and Technology, Volume 27 no. 2, August, 2007 
African Reference Frame (WAFREF) to establish a common continental and regional reference frames for Africa.

\section{DIGITAL MAPS}

Although Ghana is covered by 1:50,000 digital map, and some urban areas with 1:2500, more needs to be done in terms of digital mapping if Ghana is to benefit from GNSS and its applications. Most prospective Ghanaian applications will require large-scale digital maps hence the need for the mapping agencies especially the Survey Department of Ghana to intensify their production. Due to the multi-purpose use of the digital maps it is essential to let it conform to a required standard especially the source or provenance, time-tag or currency, reliability or correctness, precision or accuracy etc.

\section{AUGMENTATION SYSTEMS}

Africa, by virtue of its geographical position, stands to gain if Ranging and Integrity Monitoring System (RIMS) of EGNOS or WAAS is installed to augment the GNSS signals as was tried in Dakar by the EGNOS team. The use of these geostationary satellites of the SBAS will generally improve the quality of GNSS signals through the improvement of the ranging service as these satellites provide GPS-like signals to add to that received by the GPS (GNSS) satellites. The integrity of the signals improves, as it enables users to know within ten seconds whether a navigation satellite is out of tolerance (IFATCA, EVP. Europe 1999). Such augmentation will enable Ghana receive coverage of widearea differential service, and the satellite navigation precision will dramatically increase to between 5 and 10 metres. This is good enough for a good number of potential applications in the country.

Such installation should be looked at in view of the general plan of the augmentation system for Africa in general like the proposed plan for Africa India Ocean (AFI) region through the extension program of EGNOS. In addition ground based local or national augmentation system like Multipurpose GNSS Reference Stations (MGRS), Virtual Reference Station (VRS), Continuously Operating Reference Station (CORS) and others must be considered.

\section{CONTINUOUSLY OPERATING REFER- ENCE STATION (CORS)}

CORS are an important enhancement to a wide range of GPS surveying, mapping and positioning activities. They can improve the efficiency and accuracy of the activities they support and may result in a host of derived data products that in turn make possible additional GPS applications. By configuring a CORS facility in an appropriate fashion, a sponsoring organization can contribute to an effort far greater in scope than that encompassed by its own mandate. As GPS technology continuous to evolve, CORS facilities will play an increasingly more important role. To be able to get the best out of GNSS there is the need for Ghana to establish a network of reference stations, functional CORS.

A CORS basically consists of a GPS receiver, the antenna, computers, power supply and a mechanism to communicate to the outside world through broadcasting of corrections to users (telemetry). Rovers (receivers) will receive differential corrections for either real time or postprocessed data.

\section{COMMUNICATION}

There should be a telemetry component that can send signals to and from a control station, CORS, usually through wireless broadcasting, for it to link a roving receiver. This radio data link between the base and rover stations can be through the unused bandwidth of FM, UHF and VHF bands of the existing radio stations. For instance, the abundant Radio stations in Ghana will be of great benefit for such a venture. GSM and other satellite links can also be used although they are relatively expensive. Another possibility is the internet-based systems. With the rapid advances in wide accessibility of Internet technology with- 
out data transmission range limitation, an internet-based RTK system can be an efficient alternative to radio-based RTK system. (Gao, et al (2002)) The CORS can have its own telemetry system but this is usually used for a smaller coverage area unless repeaters are installed to broaden the coverage.

\section{RECEIVER TECHNOLOGY AND ACQUISITION}

The acquisition of satellite receivers by the user community is generally becoming easier with the passage of time as the receiver technology is undergoing a rapid development in miniaturization and decrease in power consumption. There is also a downward trend of the cost of the components that has resulted in a downward trend of the receiver average cost to nearly $30 \%$ per year (1) as shown in Figure 4. This means the cost of GNSS receivers is decreasing. To make an impact on the market price there should be waiver or downward adjustment of the import duties and other taxes on GNSS equipment and their accessories, to encourage their acquisition.

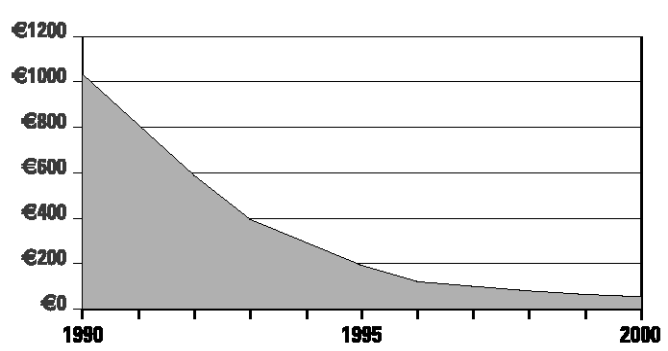

Fig. 4: Receiver Average cost

\section{NETWORK OF REFERENCE STATIONS}

To improve upon the accuracy over a wider coverage area, a network of CORS (as shown in Figure 5) can be built to cover the country. Figure 5 and Table 1, Show a scenario of $100 \mathrm{~km}$ radius coverage of 3 CORS positioned in the three most urbanized areas in Ghana: Accra, $\mathrm{Ku}-$ masi and Sekondi-Takoradi.
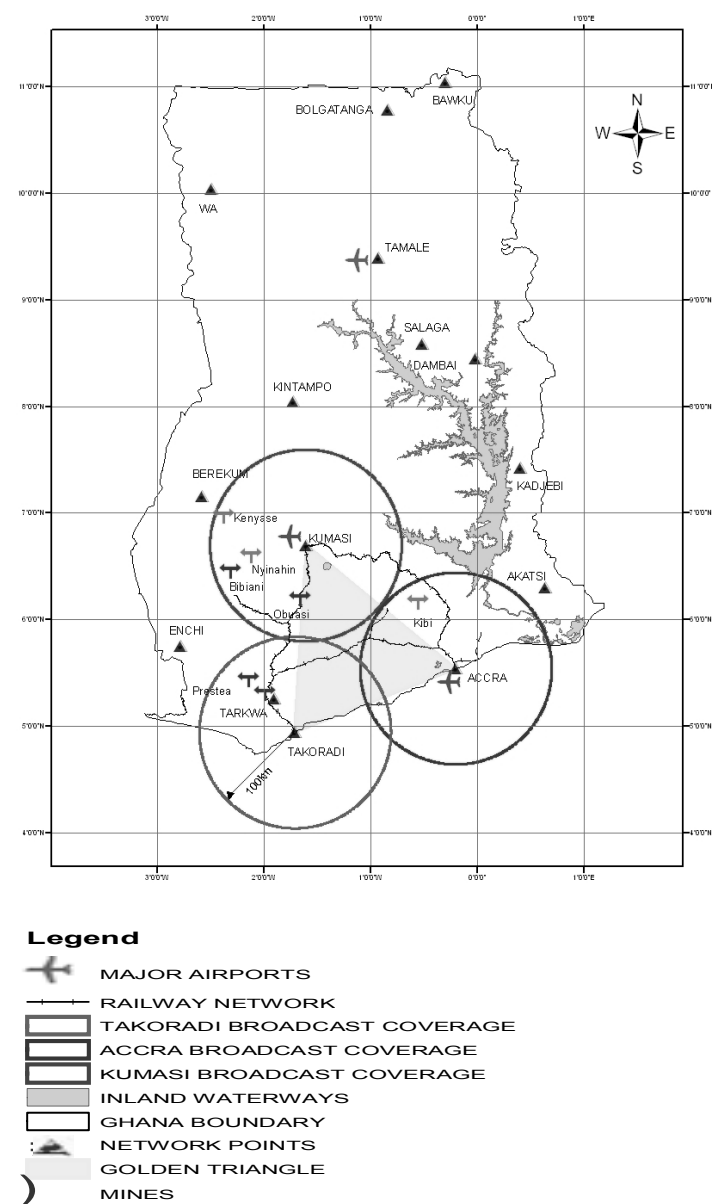

Fig. 5: Proposed National GPS Framework diagram showing the $100 \mathrm{~km}$ radius coverage of 3 CORS positioned in Accra, Kumasi and Sekondi-Takoradi

It is pertinent to note that the closer the spacing between the stations, the better the accuracy. The accuracy reduces by one metre for every $100 \mathrm{~km}$, therefore for most applications, which usually do not need sub-meter accuracies; only a few CORS will be required for the whole nation.

The scenario below represents an attempt to cover the Golden Triangle, which carries the

136 Journal of Science and Technology, Volume 27 no. 2, August, 2007 
bulk of Ghana's activities like mining, cocoa, and timber, with differential correction. The establishment of reference stations in Kumasi, Accra and Sekondi-Takoradi, that form a triangle of sides about $200 \mathrm{~km}$, will cover the three busiest highways, the whole of the railway line, over $85 \%$ of the coastline, almost all the mines in the country, $57.7 \%$ of the population and a lot more. A detailed nationwide coverage of a possible Ghana Local Area Augmentation System (GLAAS) should be designed basing the location of the CORS on factors like the national economic and social factors, infrastructural support, and potential applications, population distribution etc.

Table 1: Coverage of 3 CORS positioned in the three most urbanized areas in Ghana - Kumasi, Accra and Takoradi

\begin{tabular}{lccc}
\hline & $\begin{array}{c}\text { Coverage of } \\
\text { 100km radius } \\
\text { for 3 Broad- } \\
\text { cast Station }\end{array}$ & $\begin{array}{c}\text { Total } \\
\text { available }\end{array}$ & $\begin{array}{c}\text { Percent } \\
\text { Coverage }\end{array}$ \\
\hline Area (sq. km) & $\begin{array}{c}\text { Land: 62857 } \\
\text { Ocean: 17000 }\end{array}$ & 238,540 & 33.5 \\
$\begin{array}{l}\text { Population } \\
\text { (2000 Census) }\end{array}$ & $10.85 \mathrm{million}$ & $18.91 \mathrm{~m}$ & 57.4 \\
$\begin{array}{l}\text { Railway } \\
\text { Coastline }\end{array}$ & $953 \mathrm{~km}$ & $953 \mathrm{~km}$ & 100 \\
$\begin{array}{l}\text { Aviation- } \\
\text { Expected No. } \\
\text { of Flights }\end{array}$ & $460 \mathrm{~km}$ & $539 \mathrm{~km}$ & 85.3 \\
$\begin{array}{l}\text { Inland } \\
\text { Waterway }\end{array}$ & 16324 & 17000 & 96 \\
$\begin{array}{l}\text { Road Network } \\
\text { Major Mines }\end{array}$ & All & $1293 \mathrm{~km}$ & Below $30 \%$ \\
\hline
\end{tabular}

\section{SOME POTENTIAL APPLICATIONS}

The following are a few of the enormous potential applications relevant to the Ghanaian economy, as well as most economies in the developing world.

\section{SURVEYING}

Surveying and Mapping which is the backbone of the national development, has been undergoing transformation in the recent past. These efforts will see a great improvement if this satellite technology is fully implemented in the activities of the Survey Department. It is gratifying to note that the Survey Department. has already started using GPS for cadastral survey.

GPS is fast, simple, less expensive and independent of weather and time of the day (Fosu 2001). Propagation error, which is a problem in the conventional survey, is eliminated when GNSS is used for such surveys like the cadastral survey. More needs to be done to bring in more private survey practitioners into this technology to enhance development of the national economy.

\section{MINING}

Mining is a major component of the Ghanaian economy and the introduction of GNSS will go a long way to improve the efficiency in the mining industry and increase productivity. The expected benefit will include surveying and mapping, fleet management and environmental protection. Now GNSS plays a major role in earthworks, giving centimetre precision, this is ideal for surface mining. Also, mineral exploration both on land and sea will be greatly improved with the application of GNSS.

\section{TOURISM}

Tourism will be greatly improved if tourists are able to locate their positions through the use of navigation systems, or if a control centre can plan and monitor the trips of tourists in real time. Maps for the tourism industry need to be produced and updated fast and accurately through inexpensive means and this can be easily done with DGPS.

\section{TRAFFIC AND TRANSPORTATION}

Traffic and transportation management will really benefit from GNSS in traffic management, congestion reduction, fleet management, transportation planning etc. Road, rail and maritime applications are enormous. From land and engineering survey, through construction to the maintenance of roads and railways, GNSS plays a major role. Travel time studies, accident studies, trip planning and navigation are dominated by GNSS. 
In the field of aviation, the Ghana Civil Aviation Authority (GCAA) has made attempts to use GNSS in its operations. This includes a discussion with a US based company on international trends in aviation focused on various technologies including differential GPS (DGPS), data link, aeronautical telecommunications, and radar and air traffic management systems.

\section{AGRICULTURE}

Precision farming applications includes among others the measurement of crop yield during harvesting, management of soil samples and weeds, variable rate spreading of fertilizer. Control of fertilizer, insecticide and herbicides to ensure optimum quantities but not in excess to pollute the environment, can be achieved with autonomous farm machinery. It is even better if it is combined with satellite imagery. Tracking of animal movement by tagging them with receivers have been helping not only in agriculture but wildlife experts. Ghana being an agricultural country will benefit tremendously if through the aid of GNSS more products are gained from less space and resources.

\section{HEALTH}

Improvement on health delivery through faster and cheaper data collection methods and inputs for Health Information Systems can be easily obtained with the help of the GNSS technology. Emergency responses and search and rescue operations are enhanced through this technology. This is just to mention a few.

\section{ENVIRONMENT}

A lot has been achieved with GNSS in environmental management such as control of bush fires, early warning systems, land degradation and many others. With Ghana being threatened with deforestation and desertification, there is the need to employ this technology for quicker and near real time information to remedy any natural disasters if there is the need to sustain our development.

\section{METEOROLOGY}

The GNSS occultation method bears considerable potential for climate variability and change studies in providing a unique combination of global coverage, high vertical resolution and accuracy, long-term stability and all weather capability (Kirchengast et al 200). Accurate weather forecast is essential to Ghana as it is threatened by the downward push of the Sahara Desert. This is also very relevant as Ghana depends mainly on rainfall for her farming activities, and a lot will depend on accurate weather forecasts.

\section{DEFORMATION STUDIES}

Civil structures especially high-rise buildings; bridges, dams and others must be monitored. This is done with the precise GNSS technology. Monitoring of the earth movement can be done with the help of the highly accurate measurements made by the GPS system, which allow scientists to record millimetre-scale slip on faults that cannot ordinarily be measured. Understanding of area seismicity could lead to a better understanding of the mechanics behind earthquake and to better assessment of earthquake hazards and damage estimates. Accra earthquake-prone zone can benefit from the use of this high precision application of the GNSS.

\section{INFORMATION AND COMMUNICATION TECHNOLOGY (ICT)}

ICT, which has become the order of the day, will receive a big boost with the introduction of GNSS, as it is all about information, and about $80 \%$ of this information is spatially based, hence up-to-date digital maps are needed. Spatial information must be gathered and the use of GPS will be the means to achieve that. There are several other applications that need to be considered as a nation with the advent of GNSS.

There are several emerging applications like location-based services, leisure, policing and others that can be developed into the Ghanaian system

138 Journal of Science and Technology, Volume 27 no. 2, August, 2007 
To develop in a sustainable manner, GNSS has proved to be indispensable for both the developed and developing worlds and Africa cannot afford to be left behind.

\section{IMPLEMENTING GNSS IN GHANA}

The successful introduction of GNSS will depend on the definition and implementation of an institutional mechanism to guide a well-planned transition into the world of satellite navigation, (Henaku 1999). There is therefore the need for all professionals in GNSS and related fields to come together to analyze the strengths, weaknesses, opportunities and threats of this technology in the Ghanaian environment, then come out with a national plan on how it can be adapted in the country. For the above proposal, the following must be considered.

i) Formation of a GNSS group of experts at the national level to work towards its introduction into the country

ii) Education and sensitization of the public especially the decision-makers. Seminars and workshops must be carried out targeting decision makers and potential users on GNSS

iii) Inventory of available infrastructure that can support GNSS and the role they can play in the establishment of a functional GNSS system in Ghana should be taken studied for the best to be chosen

iv) Capacity building especially in human resources. As a step further to the establishment of postgraduate studies at KNUST in GIS, there should be an expansion into the field of GNSS to train personnel in this technology.

v) Marketing strategies to explore areas in the economy where this technology can support and how it can be sustained.

vi) To establish and develop a system that will be demand driven, and also look at related technologies like map matching, pseudolites, remote sensing and others. vii) Collaboration with international organizations and other countries should be encouraged, for example the current efforts by the Geodetic Engineering Department of Kwame Nkrumah University of Science and Technology and their German counterparts Bavaria Academy of Sciences to establish an IGS station (Ehrnsperger and Fosu 1997).

viii) Participation in the activities of the Peaceful Uses of Outer Space of the UN and other relevant bodies must be encouraged.

\section{FUNDING}

The funding should be from both internal sources for example state budget from the Ministries, Departments and Agencies of the government. Public-private partnership should be encouraged in the financing and external sources from donor agencies should be sought for. Multi national companies like the mines who will be the direct beneficiaries must be encouraged to assist in the financing. Users of the broadcast signals should access it at a cost and that will be used to fund the development and sustenance of this technology.

\section{CONCLUSION}

It is obvious from the above sections that GNSS has enormous and ever increasing potential which can be exploited for national development and poverty alleviation in a sustainable manner, especially with the improved services of GPS which is undergoing modernization, GLONASS which is increasing its orbiting satellites and the introduction of fully civilian GALILEO by the year 2008, improved GNSS is becoming more accessible around the globe. The proposed expansion of the Satellite Based Augmentation Systems, EGNOS to Africa and the improved receiver technology at affordable costs, it is imperative for Ghana as a nation to take the necessary steps to join in the search for the benefits of this space technology for the betterment of her people and be competitive in the global economy. 


\section{REFERENCES}

Ehrnsperger, W., C. Fosu (1997). Establishing a new IGS station at Kumasi.1996 International GPS Service (IGS) Report.

Fosu, C. 2001. Using GPS Technology for Surveying in Ghana. Proceedings of SERRI

Gao, Y. Liu, Z. Liu, Z.Z. (2002). Internet-Based Real-Time Kinematic Positioning GPS Solutions, Vol. 5. No 3 pp 61-69 Wiley Periodicals Inc.
Henaku, B.D.K 1999. Implementation of GNSS in Africa, Paper Presented at the Technical Forum on GNSS, UNISPACE III, 26-7-1999

IFATCA, EVP Europe (1999). A Beginner's Guide to GNSS in Europe

Kirchengast, G. et al 2000. Space borne Climate Change Monitoring by GNSS occultation sensors. Printed in AMS Preprint Vol. of the $11^{\text {th }}$ Symposium on Global Change Studies pp. $62-65,80^{\text {th }}$ AMS Annual Meeting, Long Beach CA USA

140 Journal of Science and Technology, Volume 27 no. 2, August, 2007 